\title{
Identification and isolation of kidney-derived stem cells from transgenic rats with diphtheria toxin-induced kidney damage
}

\author{
QING-ZHEN LIU ${ }^{1}$, XU-DONG CHEN ${ }^{2}$, GANG LIU ${ }^{1}$ and GUANG-JU GUAN ${ }^{1}$ \\ ${ }^{1}$ Department of Nephrology, The Second Hospital of Shandong University, Jinan, Shandong 250033; \\ ${ }^{2}$ Department of Respiratory Medicine, Shandong Jiaotong Hospital, Jinan, Shandong 250031, P.R. China
}

Received October 27, 2014; Accepted October 21, 2015

DOI: $10.3892 /$ etm.2016.3516

\begin{abstract}
Adult stem cells have been well characterized in numerous organs, with the exception of the kidneys. Therefore, the present study aimed to identify and isolate kidney-derived stem cells. A total of 12 Fischer 344 transgenic rats expressing the human diphtheria toxin receptor in podocyte cells of the kidney, were used in the present study. The rats were administered 5-bromo-2'-deoxyuridine (BrdU) in order to detect cellular proliferation. After 60 days, the rats were treated with the diphtheria toxin (DT), in order to induce kidney injury. Immunohistochemical analysis indicated that the number of BrdU-positive cells were increased following DT treatment. In addition, the expression of octamer-binding transcription factor 4 (Oct-4), a stem cell marker, was detected and suggested that kidney-specific stem cells were present in the DT-treated tissue samples. Furthermore, tissue samples exhibited repair of the DT-induced injury. Further cellular culturing was conducted in order to isolate the kidney-specific stem cells. After 5 weeks of culture, the majority of the cells were non-viable, with the exception of certain specialized, unique cell types, which were monomorphic and spindle-shaped in appearance. The unique cells were isolated and subjected to immunostaining and reverse transcription-polymerase chain reaction analyses in order to reconfirm the expression of Oct-4 and to detect the expression of Paired box 2 (Pax-2), which is necessary for the formation of kidney structures. The unique cells were positive for Oct-4 and Pax-2; thus suggesting that the identified cells were kidney-derived stem cells. The results of the present study suggested that the unique cell type identified in the kidneys of the DT-treated rats were kidney-specific stem cells that may have been involved in the repair of DT-induced tissue
\end{abstract}

Correspondence to: Dr Guang-Ju Guan, Department of Nephrology, The Second Hospital of Shandong University, 247 Beiyuan Street, Jinan, Shandong 250033, P.R. China

E-mail: guanguangju457@gmail.com

Key words: 5-bromo-2'-deoxyuridine labeling, octamer-binding transcription factor 4, paired box 2, kidney-derived stem cells, transgenic rats injury. In addition, these cells may provide a useful cell line for studying the fundamental characteristics of kidney stem cells, as well as identifying kidney-specific stem cell markers.

\section{Introduction}

The identification of tissue-specific stem cells is a key aim of current research and may potentially lead to the development of treatments for various diseases, including neurodegenerative disorders and cardiac diseases $(1,2)$. In addition, stem cells may have a vital role in the field of regenerative medicine (3). In a previous study, stem cell progeny were shown to divide at a rapid rate, whereas the turnover time of stem cells in the bone marrow and skin was comparably slow (4). Furthermore, stem cells have been shown to contribute to wound and organ repair processes following injury (5-7). Adult stem cells and their niches have been well characterized in various organs, including the bone marrow, intestines, skin, gastrointestinal mucosa, liver, prostate and brain (8-12). A single neural stem cell has been shown to differentiate into astrocytes, glia and neurons (11). However, the nature and function of kidney-specific stem cells remain unclear, with certain researchers doubting the existence of adult stem cells in the kidneys (13).

Previous studies reported that stem cells in the adult kidneys of skate and freshwater teleosts were associated with the formation of nephrons following a partial nephrectomy (14-16). In addition, bone marrow-derived stem cells were shown to migrate to the kidneys and specialize into tubular epithelial cells following acute kidney injury (17-21). During embryonic development, stem cells are present in the metanephric mesenchyme, which is the site of origin of numerous structures belonging to the mature kidney, with the exception of the collecting duct, interstitium and vasculature $(22,23)$. The present study aimed to identify and isolate kidney-derived stem cells, and to determine their function in the kidneys. In addition, the expression of octamer-binding transcription factor 4 (Oct-4) was detected, since it has previously been shown to be expressed in various types of stem cells, including embryonic stem cells, primordial germ cells, adult gonads, and stem cells isolated from umbilical cord blood, the bone marrow, hair follicles, muscle, skin, breast tissue, pancreas, liver, amniotic fluid, endothelial progenitor cells and neural stem cells (24-41). 


\section{Materials and methods}

Animals and model establishment. The animal use protocol in the present study was approved by the Animal Care and Ethical Committee at the Second Hospital of Shandong University (Jinan, China). A total of 12 Fischer 344 transgenic (Tg) rats (age, 3 days; weight, 12.5-13.5 kg), of which half were female, expressing the human diphtheria toxin receptor (hDTR; RGD_ID1302921) were used in the present study. The rats were maintained under a 12-h light/dark cycle, with ad libitum access to food and water. Kidney injury was stimulated in nine rats using the diphtheria toxin (DT; Sigma-Aldrich, St. Louis, MO, USA). The remaining three rats were used as the control. The minimum lethal dose of DT for humans has been reported to be $100 \mathrm{ng} / \mathrm{kg}$ body weight $(42,43)$. On the basis of a standardization protocol $(42,43), 10 \mathrm{ng} / \mathrm{kg}$ DT concentration was considered sufficient to induce kidney injury in the Tg rats.

5-bromo-2'-deoxyuridine (BrdU) labeling retention assay and immunohistochemical analysis. For the BrdU labeling retention assay, the $\mathrm{Tg}$ rats were injected subcutaneously with $50 \mu \mathrm{g} / \mathrm{g} / \mathrm{d} 5$-bromo-2'-deoxyuridine (BrdU; Sigma-Aldrich) for 3 days. At 60 days post-BrdU administration, the rats were sacrificed by intraperitoneal injection with $60 \mathrm{mg} / \mathrm{kg}$ body weight pentobarbital sodium (Sigma-Aldrich). Immunohistochemical analyses was performed to confirm that the BrdU was successfully incorporated into the rat kidney tissues. In order to visualize BrdU incorporation, kidney tissue sections $(4 \mu \mathrm{m})$ were deparaffinized with xylene and hydrated, during which the glass slides were dipped into isopropyl alcohol and subsequently hydrated with water (all Sigma-Aldrich). Endogenous peroxidase was inhibited using 10\% methanol in 1X phosphate-buffered saline (PBS; Sigma-Aldrich), and DNA was denatured by incubating the tissue sections with $2 \mathrm{~N} \mathrm{HCl}$ at $37^{\circ} \mathrm{C}$ for $45 \mathrm{~min}$. Nonspecific staining was blocked with $2 \%$ bovine serum albumin (BSA; Sigma-Aldrich) for $1 \mathrm{~h}$ at ambient temperature. The sections were then incubated overnight at $4^{\circ} \mathrm{C}$ with mouse anti-BrdU monoclonal antibody (1:40; B8434; Sigma-Aldrich) and goat anti-oct-4 polyclonal antibody (1:100; SAB2500713; Sigma-Aldrich). Following incubation with primary antibody, tissue sections were washed and incubated with secondary antibodies, including goat anti-mouse fluorescein isothiocyanate-conjugated immunoglobulin (Ig) G heavy and light chains (H\&L; 1:10,000; ab6785; Abcam, Cambridge, UK), donkey anti-goat Texas $\operatorname{Red}^{\circledR}$-conjugated IgG H\&L (1:10,000; ab6883; Abcam) and donkey anti-mouse Texas $\operatorname{Red}^{\circledR}$-conjugated IgG H\&L (1:10,000; ab6818; Abcam), for $1 \mathrm{~h}$ at room temperature. The prepared slides were mounted with DPX (Sigma-Aldrich) and observed under an Eclipse Ti-S fluorescent microscope (Nikon Corporation, Tokyo, Japan). Immunohistochemical analyses, using anti-Oct-4 and anti-BrdU antibodies, were performed as described in a previous study (44). In the DT-treated rats, the rats were injected with $10 \mathrm{ng} / \mathrm{kg}$ DT 60 days following BrdU administration. On day 7 post-DT injection, the DT-treated rats were sacrificed by intraperitoneal injection with $60 \mathrm{mg} / \mathrm{kg}$ body weight pentobarbital sodium and damage to the kidneys was observed by analysis of the rat urine with the Trypan blue dye (Sigma-Aldrich).
Cell culture experiments. Kidney-derived stem cells were isolated from the $\mathrm{Tg}$ rat kidneys using the following culture protocol. The rats were sacrificed by intraperitoneal injection with $60 \mathrm{mg} / \mathrm{kg}$ body weight pentobarbital sodium, after which the kidneys were surgically removed, minced and partially digested using collagenase in the presence of a trypsin inhibitor (all Sigma-Aldrich). The resulting cell suspension was washed and plated in a medium composed of 58\% Dulbecco's modified Eagle's medium-low glucose, 42\% MCDB-201 medium, 1 insulin-transferrin-selenium, BSA $(1 \mathrm{mg} / \mathrm{ml}), 0.05 \mathrm{M}$ dexamethasone, $0.1 \mathrm{mM}$ ascorbic acid 2-phosphate, $100 \mathrm{U}$ penicillin and 1,000 $\mathrm{U}$ streptomycin with $2 \%$ fetal calf serum, $10 \mathrm{ng} / \mathrm{ml}$ epidermal growth factor, $10 \mathrm{ng} / \mathrm{ml}$ platelet-derived growth factor-BB and $10 \mathrm{ng} / \mathrm{ml}$ leukemia inhibitory factor (all Sigma-Aldrich). The medium composition used for the present experiment is a slightly modified version of a medium described in a previous study (45). The cells were seeded on fibronectin-coated culture flasks (BD Biosciences, San Jose, CA, USA) at a low density $\left(300\right.$ cells $\left./ \mathrm{cm}^{2}\right)$, to avoid cell-cell contact and cultured at $37^{\circ} \mathrm{C}$ in the presence of $5 \% \mathrm{CO}_{2}$.

Immunostaining. Kidney-derived stem cells were fixed with 4\% paraformaldehyde, permeabilized with Triton X-100 (Sigma-Aldrich) and blocked with 1\% BSA in PBS for $1 \mathrm{~h}$. The cells were incubated with goat anti-oct- 4 polyclonal antibody (1:100; SAB2500713; Sigma-Aldrich) overnight at $4^{\circ} \mathrm{C}$. The plates were washed in $1 \mathrm{X}$ PBS and incubated with polyclonal horseradish peroxidase-conjugated rabbit anti-goat $\operatorname{IgG}(1: 10,000$; ab97023; Abcam) for $1 \mathrm{~h}$ in the dark at room temperature. The antibody complexes were visualized using the 3,3'-diaminobenzidine (DAB) substrate (Sigma-Aldrich). The processed plates were observed under the Nikon Ti-S fluorescent microscope. In addition, unstained cells were observed using a phase contrast microscope (ECLIPSE TS100/100-F; Nikon Corporation, Tokyo, Japan).

Reverse transcription-polymerase chain reaction (RT-PCR) analysis. Total RNA was isolated from the kidney-derived cultured stem cells using an RNeasy Mini Kit (Qiagen, Hilden, Germany) following the standard manufacturer protocol, and stored at $-70^{\circ} \mathrm{C}$. RNA was treated with DNase1 (Invitrogen, Carlsbad, CA, USA), and the quality and quantity of the RNA were validated using the NanoDrop 2000 (Thermo Fisher Scientific, Inc., Wilmington, DE, USA), according to the manufacturer's protocol. Reverse transcription was conducted using $0.5 \mu \mathrm{g}$ total RNA as a template and the ThermoScript ${ }^{\mathrm{TM}}$ RT-PCR System \& Platinum ${ }^{\circledR}$ Taq DNA Polymerase kit (Invitrogen; Thermo Fisher Scientific, Inc., Waltham, MA, USA), according to the manufacturer's protocol. PCR was performed on $1 \mu 1 \mathrm{cDNA}$ using the following primers: Oct-4, forward 5'-CTGTAACCGGCG CCAGAA-3' and reverse 5'-TGCATGGGAGAGCCCAGA-3' (Sigma-Aldrich); Pax-2, the SABiosciences RT2 PCR primer set (LOC293992; Qiagen Sciences, LLC); and glyceraldehyde-3-phosphate dehydrogenase (GAPDH), forward 5'-TGG AGAGGCCTGCCAAGTA-3' and reverse 5'-AAGAGTGGG AGTTGCTGTTG-3' (Sigma-Aldrich). PCR cycles were run under standard conditions in the T100 ${ }^{\mathrm{TM}}$ Thermal Cycler (Bio-Rad Laboratories, Inc., Hercules, CA, USA) and were as 

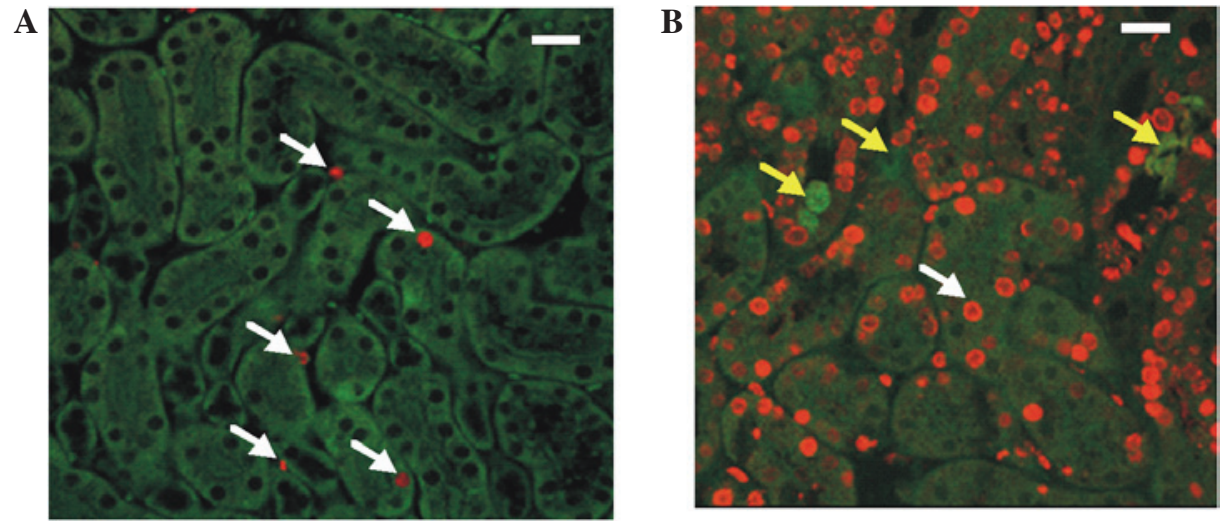

Figure 1. 5-bromo-2'-deoxyuridine (BrdU) labeling retention assay. (A) BrdU-treated control Tg rat kidney tissue section. The BrdU-positive cells (red) are marked with white arrows. (B) BrdU + diphtheria toxin (DT)-treated Tg rat kidney tissue section. DT-treated cells are marked with yellow arrows (scale bar, $50 \mu \mathrm{m})$.
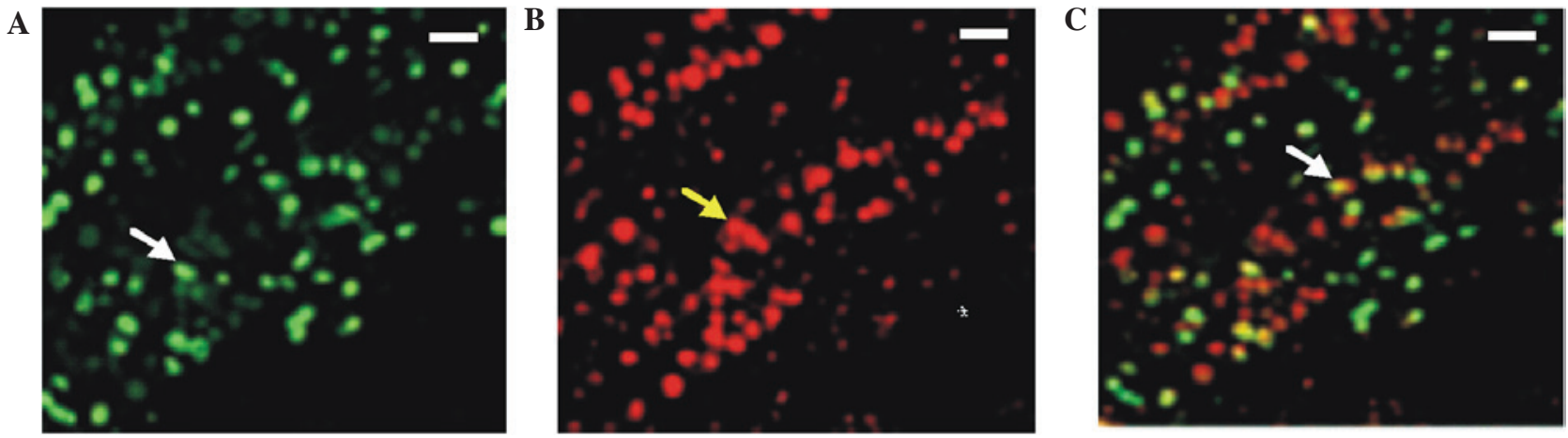

Figure 2. Immunohistochemical analysis was performed using anti-5-bromo-2'-deoxyuridine (BrdU) and anti-octamer-binding transcription factor 4 (Oct-4) antibodies. (A) BrdU-positive cells (white arrows) in the diphtheria toxin (DT)-treated Tg rat kidney section. (B) Oct-4-positive cells (yellow arrows) in the DT-treated Tg rat kidney sections. (C) Merged image of (A) and (B), showing BrdU- and Oct-4-positive cells (scale bar, $100 \mu \mathrm{m}$ ).

follows: Initial denaturation at $95^{\circ} \mathrm{C}$ for $10 \mathrm{~min}$, followed by 40 cycles of $95^{\circ} \mathrm{C}$ for $15 \mathrm{sec}$ and $60^{\circ} \mathrm{C}$ for $1 \mathrm{~min}$. PCR products were resolved in $2 \%$ agarose gel containing ethidium bromide (both Sigma-Aldrich), and were then observed and documented using a gel documentation unit (Gel Doc ${ }^{\mathrm{TM}}$ EZ System; Bio-Rad Laboratories, Inc.).

\section{Results}

BrdU labeling of Tg rats. The Tg rats were injected subcutaneously with $50 \mu \mathrm{g} / \mathrm{g} \mathrm{BrdU}$ in order to detect cellular proliferation. Immunohistochemical analysis at day 60 following BrdU labelling suggested that $\mathrm{BrdU}$ was successfully incorporated into the Tg rat kidney tissues, as demonstrated by the co-localization of anti-BrdU and anti-oct-4 antibodies (data not shown).

Injection of DT toxin. The hDTR was specifically expressed in the podocytes of the $\mathrm{Tg}$ rats. After 60 days, the Tg rats were injected with $10 \mathrm{ng} / \mathrm{kg}$ DT and the presence of dead cells in the urine was detected on day 7 following DT injection (data not shown) by staining the urine with the Trypan blue dye. The numbers of podocytes in the kidney were markedly depleted following treatment with DT. Kidney tissue samples were collected at day 10 following DT injection. Day 10 was selected as the appropriate time to collect the kidney samples based on the preliminary standardization protocol.
Identification of BrdU and Oct-4 positive cells. Kidney samples were collected from the Tg rats (including the control rats) and immunohistochemical analyses were conducted using anti-BrdU and anti-Oct-4 antibodies. BrdU-positive cells were detected in the control and DT-treated kidney tissue sections; however, the number of BrdU-positive cells in the control sections was markedly decreased, as compared with the DT-treated kidney sections (Fig. 1A and B). In addition, the DT-treated cells appeared to be renewed by the BrdU-positive cells (Fig. 1B), and these results were confirmed by immunohistochemical detection of Oct- 4 and BrdU co-expression. Therefore, these results suggested that the majority of the BrdU-positive cells were kidney-derived stem cells, since they also expressed Oct-4 (Fig. 2). These kidney-derived stem cells may be involved in the restoration or renewal of the injured or depleted cells.

Isolation and culture of kidney-derived stem cells. In order to isolate the kidney-derived stem cells, kidney samples from the $\mathrm{Tg}$ rat kidneys underwent cell culturing. Following 5 weeks of culturing, the majority of the cell types were non-viable. In addition, the cultured cells appeared monomorphic and spindle-shaped when observed under a phase contrast microscope (Fig. 3A).

Immunostaining and RT-PCR analysis. In order to confirm that the isolated cells were kidney-derived stem cells, 
A
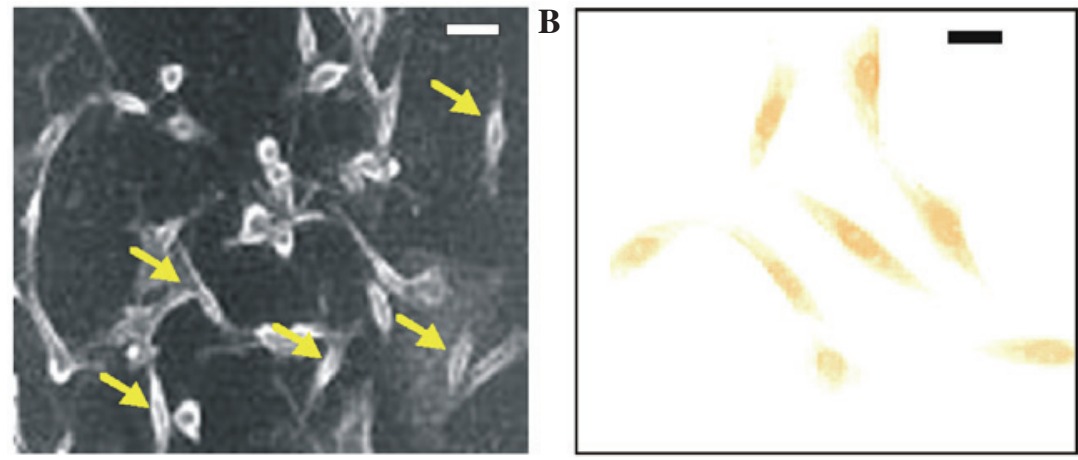

Figure 3. Isolation and characterization of kidney-derived stem cells. (A) Isolated and cultured kidney-derived stem cells (yellow arrows) imaged using a phase contrast microscope. (B) Kidney-derived stem cells subjected to immunostaining with anti-octamer-binding transcription factor 4 antibody exhibiting brown color signal with 3,3'-diaminobenzidine substrate (scale bar, $10 \mu \mathrm{m}$ ).

A

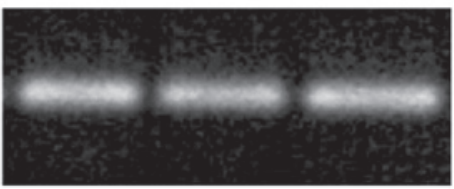

B

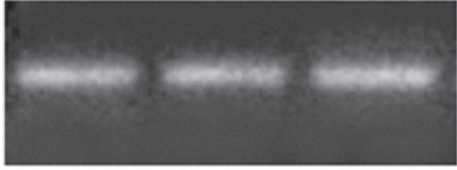

C

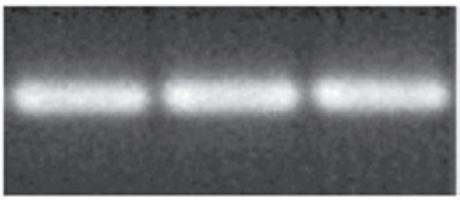

Figure 4. Reverse transcription-polymerase chain reaction analysis. Expression profile of (A) Pax-2, (B) Oct-4 and (C) GAPDH in the isolated kidney-derived stem cells. The reactions were run in triplicate. PAX-2, paired box 2; Oct-4, octamer-binding transcription factor 4; GAPDH, glyceraldehyde 3-phosphate dehydrogenase.

immunostaining was conducted using the anti-Oct-4 antibody. The Oct- 4 positive cells exhibited a dark brown coloration following staining with the DAB substrate (Fig. 3B); thus suggesting that the isolated cells were kidney-derived stem cells. Furthermore, RT-PCR was performed in order to confirm whether the Oct- 4 positive cells had originated from the kidneys. Oct-4, Pax-2 and GAPDH mRNA expression was detected in the cultured cells (Fig. 4). These results suggested that the cultured unique cells were kidney-derived stem cells.

\section{Discussion}

Kidney injury and diseases are current a major health concern. Regenerative medicine is the key to successful treatment of those diseases. Basic scientific knowledge of tissue specific stem cells is essential for the development of the field of regenerative medicine (19). Adult stem cells and their niches have been well characterized in numerous organs, including bone marrow, the intestines, skin, gastrointestinal mucosa, liver, prostate and brain (8-12). However, the function of adult stem cells specific to the kidneys remains unclear. In the present study, kidney-specific stem cells were isolated and characterized using the stem cell markers Oct-4 and Pax-2.
In order to confirm the presence of kidney-specific stem cells, the DT toxin was employed in the present experiments. It is universally known that stem cells are involved in cellular renewal and compensation when a specific tissue is under injury or affected by diseases (3). In order to establish a model of kidney injury, $10 \mathrm{ng} / \mathrm{kg}$ DT was administered to the Tg rats. By contrast, a DT concentration of $>50 \mu \mathrm{g} / \mathrm{kg}$ is toxic and has been shown to result in rat mortality within 10 days (43). Therefore, it was crucial to standardize the lower minimum concentration of DT. Furthermore, it has been reported that a DT concentration of $25 \mathrm{ng} / \mathrm{kg}$ resulted in animal survival durations of up to 28 days (43). Hence, the DT concentration selected for the present experiment was $10 \mathrm{ng} / \mathrm{kg}$, based upon careful standardization (43).

A BrdU labeling retention assay was conducted in order to confirm the presence of kidney-derived stem cells, and the results clearly indicated that the kidney samples contained tissue-specific stem cells. However, the signals obtained by the BrdU labeling retention assay suggested that not all of the BrdU-positive cells were stem cells. Therefore, to confirm the results of the preliminary BrdU labeling retention assay, immunohistochemical analyses were conducted using anti-Oct-4 and anti-BrdU antibodies. The results of the immunohistochemical analyses indicated that the majority of the BrdU-positive cells were also Oct- 4 positive; thus confirming that the BrdU-positive cells were stem cells. Therefore, on the basis of the preliminary data and subsequent immunohistochemistry results, it was concluded that the kidney tissues contained organ-specific stem cells. Notably, the kidney tissue depletion caused by $10 \mathrm{ng} / \mathrm{kg}$ DT was restored by the proliferation of the kidney-derived stem cells. This recovery may be due to the low concentration of DT injected into the Tg rats.

In order to isolate the kidney stem cells, in vitro cell culturing was performed. Certain cells behaved like stem cells following a prolonged interval. After 5 weeks of cell culture, the majority of the cells were non-viable. However, certain unique cell types were observed in the culture medium that appeared monomorphic and spindle-like in shape when observed under the phase contrast microscope. In order to confirm that these cells were stem cells, immunostaining was conducted using an anti-Oct-4 antibody. The results of the immunostaining assay clearly indicated that the unique cell types were stem cells. In order to validate this, and to confirm that the unique cell types 
were kidney-derived stem cells, RT-PCR was performed. The mRNA expression profile of Oct- 4 and Pax-2 in the unique cell types were evaluated. Pax-2 is a transcription factor that is important for kidney development. Both Oct-4 and Pax-2 were expresssed in the unique cell types; thus suggesting that they were kidney-specific stem cells. On the basis of these results, it was confirmed that the unique cell types were kidney-derived stem cells.

A previous study reported the lack of a definitive marker for kidney stem cells (13). The identification of kidney-specific markers is therefore required, which is crucial for the isolation of adult kidney stem cells and the elucidation of their role within the organ. The unique cells isolated in the present study may be used to identify accurate kidney-specific stem cell markers in future studies.

In conclusion, the results of the present study demonstrated that kidney stem cells may be involved in the restoration of cells injured by DT. In addition, the unique cell type was isolated and behaved in a manner resembling that of kidney-derived stem cells. The characteristic and identity of the unique cells was identified, and these cells may provide a useful cell line for studying the fundamental characteristics of kidney stem cells, as well as identifying kidney-specific stem cell markers.

\section{Acknowledgements}

The present study was supported by the Youth Foundation of the Second Hospital of Shandong University (grant no. Y2013010012). The authors would like to thank the Department of Nephrology at the Shandong Jiaotong Hospital (Jinan, China) for supplying the rats and supporting the project.

\section{References}

1. Lindvall O, Kokaia Z and Martinez-Serrano A: Stem cell therapy for human neurodegenerative disorders - how to make it work Nat Med 10: S42-S50, 2004.

2. Segers VFM and Lee RT: Stem-cell therapy for cardiac disease. Nature 451, 937-942, 2008.

3. Weissman IL: Stem cells: Units of development, units of regeneration and units in evolution. Cell 100: 157-168, 2000.

4. Cotsarelis G, Cheng SZ, Dong G, Sun TT and Lavker RM: Existence of slow-cycling limbal epithelial basal cells that can be preferentially stimulated to proliferate: Implications on epithelial stem cells. Cell 57: 201-209, 1989.

5. Taylor G, Lehrer MS, Jensen PJ, Sun TT and Lavker RM: Involvement of follicular stem cells in forming not only the follicle but also the epidermis. Cell 102: 451-461, 2000.

6. Lavker RM and Sun TT: Epidermal stem cells: Properties, markers, and location. Proc Natl Acad Sci USA 97: 13473-13475, 2000.

7. Beltrami AP, Barlucchi L, Torella D, Baker M, Limana F, Chimenti S, Kasahara H, Rota M, Musso E, Urbanek K, et al: Adult cardiac stem cells are multipotent and support myocardial regeneration. Cell 114: 763-776, 2003.

8. Alison MR, Poulsom R and Forbes SJ: Update on hepatic stem cells. Liver 21: 367-373, 2001.

9. Bernard-Kargar C and Ktorza A: Endocrine pancreas plasticity under physiological and pathological conditions. Diabetes 50 (Suppl 1): S30-S35, 2001.

10. Forbes SJ, Poulsom R and Wright NA: Hepatic and renal differentiation from blood-borne stem cells. Gene Ther 9: 625-630, 2002.

11. Morrison SJ, White PM, Zock C and Anderson DJ: Prospective identification, isolation by flow cytometry and in vivo self-renewal of multipotent mammalian neural crest stem cells. Cell 96: 737-749, 1999.
12. Wright NA: Epithelial stem cell repertoire in the gut: Clues to the origin of cell lineages, proliferative units and cancer. Int J Exp Pathol 81: 117-143, 2000.

13. Gupta S and Rosenberg ME: Do stem cells exist in the adult kidney? Am J Nephrol 28: 607-613, 2008.

14. Drummond IA, Mukhopadhyay D and Sukhatme VP: Expression of fetal kidney growth factors in a kidney tumor line: Role of FGF2 in kidney development. Exp Nephrol 6: 522-533, 1998.

15. Elger M, Hentschel H, Litteral J, Wellner M, Kirsch T, Luft FC and Haller $\mathrm{H}$ : Nephrogenesis is induced by partial nephrectomy in the elasmobranch Leucoraja erinacea. J Am Soc Nephrol 14: 1506-1518, 2003.

16. Salice CJ, Rokous JS, Kane AS and Reimschuessel R: New nephron development in goldfish (Carassius auratus) kidneys following repeated gentamicin-induced nephrotoxicosis. Comp Med 51: 56-59, 2001.

17. Poulsom R, Forbes SJ, Hodivala-Dilke K, Ryan E, Wyles S, Navaratnarasah S, Jeffery R, Hunt T, Alison M, Cook T, et al: Bone marrow contributes to renal parenchymal turnover and regeneration. J Pathol 195: 229-235, 2001.

18. Gupta S, Verfaillie C, Chmielewski D, Kim Y and Rosenberg ME: A role for extrarenal cells in the regeneration following acute renal failure. Kidney Int 62: 1285-1290, 2002.

19. Lin F, Cordes K, Li L, Hood L, Couser WG, Shankland SJ and Igarashi P: Hematopoietic stem cells contribute to the regeneration of renal tubules after renal ischemia-reperfusion injury in mice. J Am Soc Nephrol 14: 1188-1199, 2003.

20. Kale S, Karihaloo A, Clark PR, Kashgarian M, Krause DS and Cantley LG: Bone marrow stem cells contribute to repair of the ischemically injured renal tubule. J Clin Invest 112: 42-49, 2003.

21. Szczypka MS, Westover AJ, Clouthier SG, Ferrara JL and Humes HD: Rare incorporation of bone marrow-derived cells into kidney after folic acid-induced injury. Stem Cells 23: 44-54, 2005.

22. Herzlinger D, Koseki C, Mikawa T and Al-Awqati Q: Metanephric mesenchyme contains multipotent stem cells whose fate is restricted after induction. Development 114: 565-572, 1992.

23. Oliver JA, Maarouf O, Cheema FH, Martens TP and Al-Awqati Q: The renal papilla is a niche for adult kidney stem cells. J Clin Invest 114: 795-804, 2004.

24. Dyce PW, Zhu H, Craig J and Li J: Stem cells with multilineage potential derived from porcine skin. Biochem Biophys Res Commun 316: 651-658, 2004

25. Yeom YI, Fuhrmann G, Ovitt CE, Brehm A, Ohbo K, Gross M, Hübner K and Schöler HR: Germline regulatory element of Oct-4 specific for the totipotent cycle of embryonal cells. Development 122: 881-894, 1996.

26. Mitalipov SM, Kuo HC, Hennebold JD and Wolf DP: Oct-4 expression in pluripotent cells of the rhesus monkey. Biol Reprod 69: 1785-1792, 2003.

27. Kehler J, Tolkunova E, Koschorz B, Pesce M, Gentile L, Boiani M, Lomelí H, Nagy A, McLaughlin KJ, Schöler HR and Tomilin A: Oct4 is required for primordial germ cell survival. EMBO Rep 5: 1078-1083, 2004.

28. Jiang Y, Vaessen B, Lenvik T, Blackstad M, Reyes M and Verfaillie CM: Multipotent progenitor cells can be isolated from postnatal murine bone marrow, muscle and brain. Exp Hematol 30: 896-904, 2002.

29. Jiang Y, Jahagirdar BN, Reinhardt RL, Schwartz RE, Keene CD, Ortiz-Gonzalez XR, Reyes M, Lenvik T, Lund T, Blackstad M, et al: Pluripotency of mesenchymal stem cells derived from adult marrow. Nature 418: 41-49, 2002.

30. Schwartz RE, Reyes M, Koodie L, Jiang Y, Blackstad M, Lund T, Lenvik T, Johnson S, Hu WS and Verfaillie CM: Multipotent adult progenitor cells from bone marrow differentiate into functional hepatocyte-like cells. J Clin Invest 109: 1291-1302, 2002.

31. Reyes M, Dudek A, Jahagirdar B, Koodie L, Marker PH and Verfaillie CM: Origin of endothelial progenitors in human postnatal bone marrow. J Clin Invest 109: 337-346, 2002.

32. Yu H, Fang D, Kumar SM, Li L, Nguyen TK, Acs G, Herlyn M and $\mathrm{Xu} \mathrm{X}$ : Isolation of a novel population of multipotent adult stem cells from human hair follicles. Am J Pathol 168: 1879-1888, 2006.

33. Baal N, Reisinger K, Jahr H, Bohle RM, Liang O, Münstedt K, Rao CV, Preissner KT and Zygmunt MT: Expression of transcription factor Oct-4 and other embryonic genes in CD133 positive cells from human umbilical cord blood. Thromb Haemost 92: 767-775, 2004. 
34. D'Ippolito G, Diabira S, Howard GA, Menei P, Roos BA and Schiller PC: Marrow-isolated adult multilineage inducible (MIAMI) cells, a unique population of postnatal young and old human cells with extensive expansion and differentiation potential. J Cell Sci 117: 2971-2981, 2004.

35. Davis SF, Hood J, Thomas A and Bunnell BA: Isolation of adult rhesus neural stem and progenitor cells and differentiation into immature oligodendrocytes. Stem Cells Dev 15: 191-199, 2006.

36. Romagnani P, Annunziato F, Liotta F, Lazzeri E, Mazzinghi B, Frosali F, Cosmi L, Maggi L, Lasagni L, Scheffold A, et al: CD14+ CD34 low cells with stem cell phenotypic and functional features are the major source of circulating endothelial progenitors. Circ Res 97: 314-322, 2005.

37. Romero-Ramos M, Vourc'h P, Young HE, Lucas PA, Wu Y, Chivatakarn O, Zaman R, Dunkelman N, el-Kalay MA and Chesselet MF: Neuronal differentiation of stem cells isolated from adult muscle. J Neurosci Res 69: 894-907, 2002.

38. Trosko JE and Tai MH: Adult stem cell theory of the multi-stage, multi-mechanism theory of carcinogenesis: Role of inflammation on the promotion of initiated stem cells. Contrib Microbiol 13: 45-65, 2006.

39. Tsai MS, Hwang SM, Tsai YL, Cheng FC, Lee JL and Chang YJ: Clonal amniotic fluid-derived stem cells express characteristics of both mesenchymal and neural stem cells. Biol Reprod 74: 545-551, 2006.
40. Xiao J, Nan Z, Motooka Y and Low WC: Transplantation of a novel cell line population of umbilical cord blood stem cells ameliorates neurological deficits associated with ischemic brain injury. Stem Cells Dev 14: 722-733, 2005.

41. Zhou YF, Fang F, Fu JR, Dong YS, Ye DY, Shu SN, Zhen H and Li G: An experimental study on astrocytes promoting production of neural stem cells derived from mouse embryonic stem cells. Chin Med J (Engl) 118: 1994-1999, 2005.

42. Pappenheimer AM Jr: The story of a toxic protein, 1888-1992. Protein Sci 2: 292-298, 1993.

43. Wharram BL, Goyal M, Wiggins JE, Sanden SK, Hussain S, Filipiak WE, Saunders TL, Dysko RC, Kohno K, Holzman LB and Wiggins RC: Podocyte depletion causes glomerulosclerosis: Diphtheria toxin-induced podocyte depletion in rats expressing human diphtheria toxin receptor transgene. J Am Soc Nephrol 16: 2941-2952, 2005.

44. Maeshima A, Sakurai H and Nigam SK: Adult kidney tubular cell population showing phenotypic plasticity, tubulogenic capacity and integration capability into developing kidney. J Am Soc Nephrol 17: 188-198, 2006.

45. Gupta S, Verfaillie C, Chmielewski D, Kren S, Eidman K, Connaire J, Heremans Y, Lund T, Blackstad M, Jiang Y, et al: Isolation and characterization of kidney-derived stem cells. J Am Soc Nephrol 17: 3028-3040, 2006. 